\title{
BAHIA HUMORÍSTICA DE EULÁLIO MOTTA: ESTUDO DAS UNIDADES FRASEOLÓGICAS EM CAUSOS SERTANEJOS (1933-1934)
}

\author{
Sérgio dos Santos Santana ${ }^{1}$; Liliane Lemos Santana Barreiros ${ }^{2}$; \\ 1. Bolsista PIBIC/CNPq, Graduando em Letras: Português e Espanhol, Universidade Estadual de Feira de Santana, e-mail: \\ sergio.uefs@gmail.com \\ 2. Orientadora, Departamento de Letras e Artes, Universidade Estadual de Feira de Santana, e-mail: lilianebarreiros@uefs.br
}

PALAVRAS-CHAVE: Eulálio Motta; Causos sertanejos; Unidades Fraseológicas.

\section{INTRODUÇÃOO}

Eulálio de Miranda Motta nasceu na cidade de Mundo Novo-BA, em 15 de abril de 1907 e faleceu em 15 de outubro de 1988. De formação, Eulálio Motta era farmacêutico, mas logo mostrou interesse pela literatura. "No seu processo de escrita, Eulálio Motta observava in loco, fazia anotações em cadernos e depois utilizava as informações coletadas para produzir seus textos" (BARREIROS, 2017, p. 18).

No plano de trabalho 2018/2019 PIBIC/CNPq foi proposto estudar as unidades fraseológicas (UFs) presentes nos 50 causos sertanejos de Eulálio Motta. De acordo com Barreiros (2016), os causos sertanejos que compõem o livro Bahia Humorística mostram o comportamento dos trabalhadores rurais e retratam suas práticas culturais e usos da língua. Esses registros revelam-se uma verdadeira oportunidade de pesquisa, já que traz muitas informações sobre o falar regional, além de refletir a sociocultura do homem sertanejo. Tendo em vista a qualidade do trabalho realizado por Eulálio Motta, Barreiros (2016) afirma que o autor "[...] soube utilizar as unidades fraseológicas com propriedade e assim enriquecer os seus textos [...]" (BARREIROS, 2016, p. 162).

Portanto, o estudo do léxico presente nos 50 causos escritos por Eulálio Motta revela, por meio das unidades fraseológicas, uma verdadeira riqueza cultural, pois evidencia o modo de falar e se expressar dos falantes de uma determinada região. As unidades fraseológicas identificadas na escrita de Eulálio Motta mostram seus traços linguísticos (BARREIROS, L.; TELLES, C., 2017, p. 32). Dessa forma, o presente estudo consiste na construção de um glossário apresentando as unidades fraseológicas encontradas no referido corpus, sua classificação (colocação; locução e enunciado fraseológico), segundo Corpas Pastor (1996), e o contexto das ocorrências. 


\section{METODOLOGIA}

Após a identificação e a realização do inventário das UFs presentes nos causos sertanejos, realizou-se a análise e a classificação: Esfera I - Colocações; Esfera II - Locuções e Esfera III - Enunciados fraseológicos, que se subdividem em parêmias (enunciados de valor específico, citações e provérbios) e fórmulas de rotina (fórmulas discursivas e fórmulas psicossociais), segundo os critérios de Corpas Pastor (1996), que são descritos no quadro 1:

Quadro 1 - Aspectos que distinguem as classificações das unidades fraseológicas

\begin{tabular}{|c|c|c|}
\hline Esfera I - Colocações & Esfera II - Locuções & $\begin{array}{l}\text { Esfera III - Enunciados } \\
\text { fraseológicos }\end{array}$ \\
\hline Unidades estáveis; & $\begin{array}{l}\text { Não constituem enunciados } \\
\text { completos; }\end{array}$ & Enunciados completos de fala; \\
\hline $\begin{array}{l}\text { Sintagmas livres, gerados a } \\
\text { partir de regras; }\end{array}$ & $\begin{array}{l}\text { Unidades fraseológicas do } \\
\text { sistema da língua; }\end{array}$ & Constituem atos de fala; \\
\hline $\begin{array}{l}\text { Apresenta certo grau de } \\
\text { restrição combinatória. }\end{array}$ & $\begin{array}{l}\text { Institucionalização, estabilidade } \\
\text { sintático-semântica. }\end{array}$ & Fixação interna (material). \\
\hline
\end{tabular}

Fonte: Corpas Pastor (1996, p. 132)

Desse modo, através das classificações desenvolvidas pela autora, foi possível trabalhar com a taxonomia de maneira mais concreta, uma vez que ela reúne em seu Manual de Fraseologia (CORPAS PASTOR, 1996), muitas informações e contribuições de outros autores que se debruçam sobre o campo da Fraseologia. Junto às etapas anteriores, foram realizadas leituras de outros trabalhos teóricos e de aplicação sobre o assunto (ZULUAGA, 1980; MONTORO DEL ARCO, 2006; CHRENKOVÁ, 2010; entre outros).

$\mathrm{Na}$ fase final, construiu-se um glossário com as UFs encontradas. Para a elaboração do mesmo, foram utilizados os recursos do Microsoft Word, pois apresenta muitas funcionalidades que deram conta da proposta, embora haja ferramentas próprias para a elaboração de dicionários, vocabulários e glossários. Na organização do glossário, adotou-se os critérios lexicográficos do Vocabulário de Eulálio Motta (BARREIROS, 2017a). A macroestrutura do glossário foi organizada em ordem alfabética, numa perspectiva semasiológica, que parte da forma (significante) para o significado. A microestrutura, por sua vez, foi configurada da seguinte forma:

[...] a entrada lexical, grafada em negrito, com letras minúsculas, seguida da forma básica dicionarizada entre colchetes (sendo os substantivos e os adjetivos no masculino e singular, exceto nas pluralia tantum, e os verbos no infinitivo), e as variantes entre parênteses, antecedida pela abreviação (var.). [...] As lexias complexas (colocações, locuções e enunciados fraseológicos parêmias e fórmulas de rotina) foram classificadas [...]. Em seguida, tem-se a 
definição, com o significado que remete à situação discursiva. Logo após, seguem-se as abonações, em itálico, identificadas com o código [e a linha], correspondente ao texto consultado (BARREIROS, 2017a, p. 163).

\section{RESULTADOS}

Após a leitura dos causos e identificação das unidades fraseológicas, foi realizado um inventário para possibilitar melhor visualização e análise, como mostra a figura 1:

Figura 1 - Exemplo do inventário das UFs

IVENTÁRIO DAS UNIDADES FRASEOLOGICAS NOS CAUSOS SERTANEJOS DE EULALIO MOTTA

\begin{tabular}{|c|c|c|c|c|}
\hline 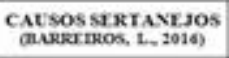 & EF & $\begin{array}{l}\text { PiGrse, } \\
\text { LIVIA }\end{array}$ & 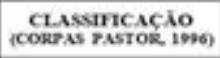 & 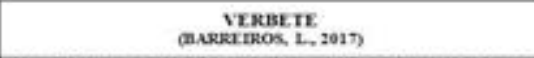 \\
\hline $\begin{array}{l}\text { C1[1939] } \\
\text { PROFESSOR } \\
\text { PRANCELINO }\end{array}$ & - competir ctem o mestre & p. 79.90 & Locędes (Loc. Adj.) & 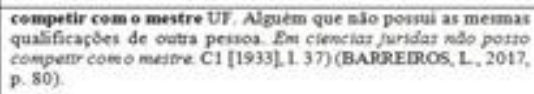 \\
\hline $\begin{array}{l}\text { C2[1933] } \\
\text { VIDA SERTANEAA I }\end{array}$ & - dá pra vidilia & $\begin{array}{l}\text { p. } 81 \\
1.11\end{array}$ & $\begin{array}{l}\text { - Colocasdes (V) prop-s } \\
\text { (obj) }\end{array}$ & 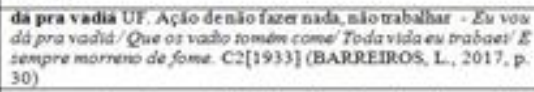 \\
\hline $\begin{array}{l}\text { CI[1939] } \\
\text { VDA SERTANEA II }\end{array}$ & - tocou pru & $\underset{1.10}{p .82}$ & $\begin{array}{l}- \text { Colocasdec (V.preptos } \\
\text { (obj.) }\end{array}$ & 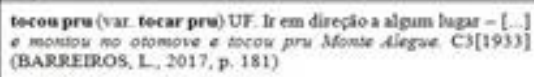 \\
\hline $\begin{array}{l}\text { CAt1933] } \\
\text { VDDA SERTANEJA m }\end{array}$ & - vivê dipindurado & $\begin{array}{l}p .83 \\
1.8\end{array}$ & Colocascles (V-Subat) & 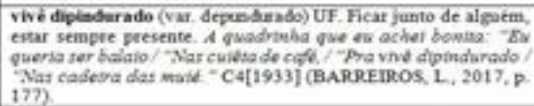 \\
\hline
\end{tabular}

Fonte: Elaborado pelos autores.

As unidades fraseológicas foram organizadas semasiologicamente para a composição de um glossário, segundo as orientações de Barreiros (2017), como se demonstra na figura 2:

Figura 2 - Organização do glossário das unidades fraseológicas

\section{A a}

\begin{abstract}
á cata do Colocaçāo $S+$ prep. $+S$. A procura de alguma coisa, de alguèm. Com isto o prefeito se aztreta e manda a policia á cata do malereado. (C27[1933], 1. 14-15).

a cuma tá dano? [como está dando] Locução (Loc. verbal). (var. a cuma é isto?). Significa perguntar o preço de alguma mercadoria. Quanto custa? Chega funto dum saco de milho, apanha um punhado, olha quebra um carbco "no dente" e pergunta ao vendedor: - "A cuma tá dano? (C8[1933], 1.5).
\end{abstract}

abra os quarto pru á intra Colocação $V+(p r e p,+) S$ (objeto). Fazer com que o corpo fique mais fresco; arejar-se nas partes intimas. Abra os quarto pru á intra, Dona Marla! Isto assim fechado fäiz mál Abra os quarto! (C18[1933], 1. 17).

abri os óio [abrir os olhos] Colocação $(V+S)$ Alertar alguém. Eu bem dizia a Maria; bem qui the abri os bio. (C46[1933], 1. 35-36).

Fonte: Elaborado pelos autores.

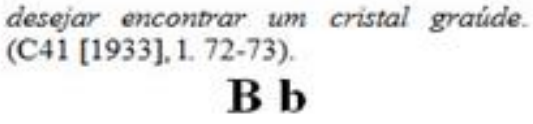

deserar encontrar um cristal graude. (C41 [1933], 1. 72-73).

\section{B b}

bota a boca no mundo [botar a boca no mundo] Colocação (S+prep. $+S)$. Denunciar; reivindicar. [...] ás $4 e^{1 / 2} d a$ manha, bota a boca no mundo, gritando a fliha: [...]. (C44[1933],1.5-6).

botar "aquilo" em pratos limpos (var. colocar em pratos limpos). Colocaçào $V+$ (prep + ) $S$ (objero) Esclarecer algum assunto. Ermiro procurou botar "aquilo" em pratos limpos. . (C20[1933],1.8-9)

botaram chucalho (var, colocar chucalho) Colocação $V+S$. Alguém que nảo passa sem ser notado. Estes andaram pela cidade toda, a dizer, em cochichos e risadas, que "botaram chucalho no velho." (C35[1933]. 1. 12-13).

\section{C c}


Ao final do trabalho, foram identificadas 24 colações, 44 locuções e 15 enunciados fraseológicos, que se subdividem em 10 parêmias e 5 fórmulas de rotina.

\section{CONSIDERAÇÕES FINAIS}

A pesquisa com unidades fraseológicas exigiu leituras, informações, questionamentos e prática no tratamento dos dados, a fim de consolidar o ato de pesquisar, que sem dúvida, foi uma realização maravilhosa para o aprimoramento de saberes e o afloramento de conhecimentos outros. Sem dúvidas, o ingresso ao mundo da pesquisa acadêmica é um momento importante para o desenvolvimento do estudante, pois proporciona desenvolvimento intelectual e profissional do acadêmico.

Essa pesquisa poderá contribuir para futuros trabalhos no campo dos estudos do léxico, em especial, da Fraseologia. Além de auxiliar para o fortalecimento da pesquisa regional/local, que é de suma importância para que autores que não estão entre os cânones sejam postos à luz das pesquisas. Os resultados obtidos contribuíram de maneira efetiva para o estudo do vocabulário de Eulálio Motta e ampliaram as discussões no âmbito do Projeto de Pesquisa Estudos lexicais no acervo de Eulálio Motta (UEFS/CONSEPE 137/2017).

\section{REFERÊNCIAS}

BARREIROS L. L. S.; TELLES, C. M. As unidades fraseológicas no vocabulário de Eulálio Motta. ReVEL, vol. 15, n.29, 2017b.

BARREIROS, Liliane L. S. Vocabulário de Eulálio Motta. 360f. Tese (Doutorado Programa de Pós-Graduação em Língua e Cultura). Universidade Federal da Bahia, Instituto de Letras, Salvador, 2017a.

BARREIROS, Liliane L. S. Bahia Humorística: causos sertanejos de Eulálio Motta. Feira de Santana-BA: UEFS Editora, 2016.

CHRENKOVÁ, Soňa. El tratamiento de las unidades fraseológicas en la lexicografía español-eslovaca. Brno-střed: Masarykova univerzita, 2010.

CORPAS PASTOR, Gloria. Manual de fraseología española. Madrid: Gredos, 1996.

MONTORO DEL ARCO, E. T. Teoría Fraseológica de las locuciones particulares. Las locuciones prepositivas, conjuntivas y marcadoras del español. Frankfurt: Peter D. Lang, 2006.

UEFS/CONSEPE. Resolução CONSEPE No 137/2017. Aprova o Projeto de Pesquisa Estudos lexicais no acervo de Eulálio Motta, sob a coordenação da Profa. Dra. Liliane Lemos Santana Barreiros, do Departamento de Letras e Artes, desta Universidade. Feira de Santana-BA: D.O.E., 12 dez. 2017.

ZULUAGA, A. Introducción al estudio de las unidades fijas. Frankfurt am Maim: Peter Lang, 1980. 